\title{
The Issue at a Glance
}

\section{Testing the Tests for Racism}

Wilfred Reilly, Kentucky State University

By almost every metric available to social science, racism in America has been in sharp decline for decades and continues its downward trajectory today. This is not true of the "audit" studies conducted primarily by sociologists, and which appear to demonstrate that people of color confront intense bias at every level of the job and housing markets. Political scientist Wilfred Reilly assesses the veracity of this research.

\section{Reviving American Higher Education: An Analysis and Blueprint for Action Gerson Moreno-Riaño, Cornerstone University}

University president Gerson Moreno-Riaño believes most of the problems he observes in higher education are rooted in the unexamined rejection of Western civilization's moral tradition, demonstrably embodied in the vision of America's Founders. This malady, he says, requires moral correction and meaningful accountability.

The Devolution of Psychological Science: Memes, Culture, and Systemic Racism

John Staddon, Duke University

Two recent articles by Shinobu Kitayama, 2020 President of the Association for Psychological Science, provide Duke psychologist John Staddon an opportunity to discuss what a successful model of social science looks like, and to highlight how far the social sciences have strayed from that model. 


\section{Campuses as Faux Nations}

George R. La Noue, University of Maryland Baltimore County

Universities and colleges resemble nothing so much as separate sovereign nations, adopting rules and regulations that clearly deprive students and staff of constitutionally protected rights and liberties. University of Maryland professor George R. La Noue examines how this came to be and how the courts might effectuate change.

\section{Fair or Foul in Interracial Discourse}

Dan Subotnik, Jacob D. Fuchsberg Law Center at Touro College

Having experienced a microaggression training class at his law school, professor Dan Subotnik suggests this kind of training may not be the most felicitous tool for cultivating mutual respect among racial groups.

\section{The New Gilded Age: We've Seen It All Before}

Wight Martindale Jr., National Association of Scholars

An analysis of several social benchmarks, including wealth distribution, corruption, the power of elites, and the marginalization of blacks convinces Wight Martindale that America today closely resembles the period of the Gilded Age. Here's how this might play out.

\section{Critical Theory vs. "Mostmodernism"}

William L. Krayer, counsel to Pittsburgh intellectual property law firm Beck and Thomas, P.C. (ret.)

Critical Theory holds that capitalism privatizes the benefits of knowledge through systems of patent and copyright laws, leaving marginalized communities alienated not only from material progress but from "ways of knowing and relating to the world." Intellectual property law expert William L. Krayer believes the critical theorists have it exactly backwards, and that the system of intellectual property protection has allowed continuous improvements in science and technology to the benefit of all. 


\section{The Politicization of Education Research and the AERA}

Richard Phelps, Nonpartisan Education Review (nonpartisaneducation.org)

Like many science-related professional associations founded on the principles of unbiased research, nonpartisanship, and best practices, the American Educational Research Association (AERA) has become thoroughly politicized.

\section{Poisoning the Well of Art Education}

Michelle Marder Kamhi, Aristos, an online review of the arts.

Art education has been gravely damaged by its practitioners' obsession with antiracism, replete with efforts to "decenter" whiteness and "Western aesthetics" and the promotion of Critical Race Theory.

\section{A Conservative Prof. Sees the Enemy ... And It Is Us!}

Seth Forman, National Association of Scholars

A conservative professor's defense of the university as a place where "political ideas can be openly debated" is contravened by a massive new study on academic freedom.

\section{Sir Roger Scruton: Good, Beautiful, True}

Steven Kessler, Russell Kirk Center for Cultural Renewal

Steven Kessler remembers the English philosopher Roger Scruton, who believed the traditions, rituals, and institutions bequeathed to us by our ancestors were the keys to human well-being. 